\title{
Belgeo
}

Revue belge de géographie

\section{De rol van terrestrisch Sub-Antarctica binnen het klimaatsonderzoek op wereldvlak}

The role of sub-Antarctic islands in global climate studies

\section{Nathalie Van der Putten}

\section{(2) OpenEdition}

\section{Journals}

\section{Édition électronique}

URL : http://journals.openedition.org/belgeo/12112

DOI : $10.4000 /$ belgeo. 12112

ISSN : 2294-9135

Éditeur :

National Committee of Geography of Belgium, Société Royale Belge de Géographie

\section{Édition imprimée}

Date de publication : 30 septembre 2006

Pagination : 373-388

ISSN : 1377-2368

\section{Référence électronique}

Nathalie Van der Putten, « De rol van terrestrisch Sub-Antarctica binnen het klimaatsonderzoek op wereldvlak », Belgeo [Online], 3 | 2006, Online op 30 octobre 2013, geraadpleegd op 19 avril 2019. URL : http://journals.openedition.org/belgeo/12112 ; DOI : 10.4000/belgeo.12112

Ce document a été généré automatiquement le 19 avril 2019.

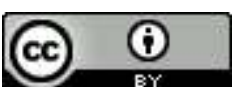

Belgeo est mis à disposition selon les termes de la licence Creative Commons Attribution 4.0 International. 


\title{
De rol van terrestrisch Sub-Antarctica binnen het klimaatsonderzoek op wereldvlak
}

The role of sub-Antarctic islands in global climate studies

\author{
Nathalie Van der Putten
}

\section{Inleiding}

1 Het klimaat van de aarde is in het "recente" verleden, het Quartair, niet stabiel geweest maar was een opeenvolging van omvangrijke koudere en warmere perioden (glacialen en interglacialen). Kleinere (kortere en plotse) schommelingen (events) hebben zich voorgedaan tijdens glaciale periodes waardoor men een verdere opdeling heeft gemaakt in stadialen (relatief koud) en interstadialen (relatief warm). Het is dan ook in het verleden dat de bron ligt om klimaatveranderingen te bestuderen en vooral om de oorzaken en de gevolgen van die klimaatveranderingen te achterhalen. Het begrijpen van de wisselwerking tussen de atmosfeer, de oceanen en de continenten bij veranderingen in het klimaat zijn cruciaal om de gevolgen in de verschillende delen van de wereld te kunnen bepalen. Wegens hun extreme omstandigheden hebben de poolgebieden een belangrijke rol gespeeld in de sturing van de klimaatsevolutie. Deze tekst heeft tot doel de bijdrage van ons eigen onderzoek op de sub-Antarctische eilanden in het geheel van het paleoklimatologisch onderzoek voor te stellen.

\section{Methoden}

De evolutie van het klimaat kan voornamelijk uit drie bronnen gereconstrueerd worden. Twee daarvan zijn terug te vinden op het land namelijk sedimenten en landijs. De derde bron is (diep)zeesedimenten. Voor elk van deze bronnen zijn specifieke technieken 
ontwikkeld om variaties in neerslag maar vooral in temperatuur, door de tijd heen te registreren.

Zo maakt men in het geval van ijskernen van zowel de Groenlandse als de Antarctische ijskap gebruik van zuurstofisotopenonderzoek ${ }^{1}$ van het ijs. Veranderingen in de verhouding tussen het zwaardere ${ }^{18} \mathrm{O}$ en het lichtere ${ }^{16} \mathrm{O}$ in polair ijs hangen samen met de temperatuur boven de ijskap op het moment dat het ijs is gevormd. Door de wijzigingen in die verhouding uit te zetten t.o.v. een diepte- en/of tijdsas kan men de schommelingen van de temperatuur in het verleden reconstrueren.

4 Op het land wordt de reactie van organismen op klimaatswijzigingen als techniek gebruikt. De bekendste en meest gebruikte techniek is palynologie (pollenanalyse, onderzoek van fossiele stuifmeelkorrels in veen- of meersedimenten). Direkt aanleunend hierbij kan macrorestenonderzoek van planten- en insektenresten, bewaard in anaerobe omstandigheden (veen- en meersedimenten), eveneens tot een klimaatscurve leiden. Verder zal hier een specifiek voorbeeld van een dergelijk onderzoek worden toegelicht. Ook lagere organismen zoals diatomeëen en thecamoeben zijn zeer bruikbare proxies in het kader van klimaatsonderzoek.

In het geval van diepzeekernen kan men stellen dat beide bovengenoemde technieken worden toegepast. De meest gebruikte proxy in dit geval zijn fossiel bewaarde foraminiferen in zeesedimenten. Men kan via de ecologie van deze micro-organismen nagaan of het oceaanwater relatief kouder of warmer is geweest op het moment dat ze leefden.

6 Aangezien zuurstof aanwezig is in het kalkskelet dat fossiel wordt teruggevonden, kan men eveneens ${ }^{18} \mathrm{O} /{ }^{16} \mathrm{O}$ toepassen. Tijdens een glaciale periode wordt water dat verdampt boven de oceanen opgeslagen in de aangroeiende ijskappen met als gevolg dat het aandeel aan ${ }^{18} \mathrm{O}$ in het oceaanwater gaat stijgen en bijgevolg ook in de kalkskeletten van de organismen. Zuurstofisotopenonderzoek van foraminiferen geeft dus een evolutie in de tijd weer van het volume ijs dat opgeslagen is op de continenten en vormt dus een aanduiding van koudere en warmere perioden (Magny, 1995). De isotoopschommelingen in deze sedimentsequenties worden aangeduid als marine-isotope-stages (MIS) waarbij de oneven getallen duiden op warme perioden (Holoceen is MIS1, het Eemiaan is MIS 5e) en de even getallen op koudere perioden (Westerhoff et al., 2003).

7 Zee- en ijskernen hebben ten opzichte van landsedimenten het voordeel dat hun registratie continu is zowel tijdens glacialen als tijdens interglacialen terwijl op het land erosie een belangrijke factor is in het verstoren van stratigrafische sequenties.

\section{Datering}

Een essentieel gegeven voor alle bronnen en technieken is het (absoluut en/of relatief) dateren van de sedimenten of het ijs. Dit is uiteraard belangrijk op zich, maar ook om resultaten te kunnen vergelijken binnen éénzelfde techniek of nog, tussen de technieken onderling.

In ijskernen wordt de tijdsas opgesteld aan de hand van het tellen van de ijslaagjes die jaarlijks worden afgezet (verschil in verhouding van $\mathrm{O}^{18} / \mathrm{O}^{16}$ tussen zomer en winter) tot een bepaalde diepte. Op grotere diepten wordt "geëxtrapoleerd". In de GRIP-kern (European Greenland Ice Core Project), genomen op het hoogste punt van de Groenlandse ijskap en met een lengte van 3028 m (Dansgaard et al., 1993), werd de gelaagdheid geteld 
tot 14,5 kyr BP (thousands of years Before Present), wat overeenkomt met een diepte van ongeveer $1750 \mathrm{~m}$. Dieper werd de tijdsas berekend aan de hand van modellering van de ijsbeweging. Het spreekt vanzelf dat bij deze modellen de ingevoerde parameters (compactie van de laagjes, onverstoorde stratigrafie...) belangrijk zijn en dat de bekomen tijdsas niet zo "absoluut" is als bij het tellen van laagjes.

In het geval van landsedimenten wordt als absolute dateringsmethode koolstofdatering gebruikt op organisch materiaal. De koolstof ouderdom wordt uitgedrukt in ${ }^{14} \mathrm{C}$ jaren Before Present $(B P=$ Before 1950). De concentratie aan radioactieve koolstof in de atmosfeer was echter niet steeds constant waardoor de ${ }^{14} \mathrm{C}$-ouderdom niet de ware ouderdom is. Wanneer men dus de effectieve ouderdom (uitgedrukt in cal BP) wil weten moet er gekalibreerd worden via een kalibratiecurve, opgesteld aan de hand van dendrochronologisch onderzoek.

11 Het dateren van diepzeesedimenten gebeurt absoluut door ${ }^{14} \mathrm{C}$-datering (Sánchez Goni $e t$ al., 2000, Bond et al., 1993) tot 40000 jaar terug en voor oudere sedimenten wordt de uranium-thorium methode gebruikt (tot 350000 jaar terug). Aan de hand van ${ }^{18} \mathrm{O} /{ }^{16} \mathrm{O}$ curven van foraminiferen kan relatief gedateerd worden. Hiervoor verwijzen we onder andere naar een publicatie van Martinson et al. (1987) waarin aan de hand van orbital tuning (koppeling met de orbitale klimaatsinformatie) een continue chronostratigrafie voor de diepzee is opgesteld voor de laatste 300000 jaar.

\section{Pre-holocene klimaatswijzigingen}

\section{Noordelijk Halfrond}

Uit onderzoek van land-, zee- en ijskernen werd duidelijk dat het klimaat tijdens het Quartair allesbehalve stabiel is geweest en dat verschillende glacialen en interglacialen te herkennen zijn, waarbinnen verder stadialen en interstadialen voorkomen.

De Groenlandse GRIP-ijskern (Dansgaard et al., 1993) waarvan sprake hierboven, geeft een gedetailleerde isotopenstratigrafie die teruggaat tot 250000 jaar geleden waarin zeer abrupte klimaatswijzigingen waargenomen worden, zowel in de glaciale als interglaciale periodes (behalve het Holoceen). Deze snelle koud-warm oscillaties worden Dansgaard/ Oeschger events ${ }^{2}$ (D/O events) genoemd. In het laatste glaciaal (14-115 kyr BP) zijn 24 events vastgesteld.

Bond et al. (1993) hebben voor de laatste 90.000 jaar de $\delta^{18} \mathrm{O}$ van de GRIP-ijskern gecorreleerd met de wijzigingen in Sea Surface Temperature (SST), bekomen uit twee Noord-Atlantische zeekernen (aan de hand van de planktonische foraminifeersoort Neogloboquadrina pachyderma). Zij kwamen tot de conclusie dat zowel in de ijskern als in de zeekernen een bijzondere cyclus aanwezig was die correlatie toeliet ondanks de relatief onzekere chronologieën van de drie kernen. Deze "Bond cycli" bestaan uit het bundelen van verscheidene steeds kouder wordende D/O events in langere koude cycli die elk beëindigd worden door een plotse overgang van een zeer koude naar een warme temperatuur. Bovendien culmineert elke Bond cyclus in een enorme uitbreiding van ijsbergen in de Noord Atlantische oceaan (Heinrich event ${ }^{3}$ net voor de plotse opwarming.

Men gaat ervan uit dat op de breedten waar de zeekernen zijn genomen de veranderingen in de SST in fase moet zijn met de veranderingen in de lucht temperatuur boven Groenland, zeker op de momenten waar de scherpe temperatuurstijgingen op het einde 
van de D/O cycli voorkomen. De correlatie gebeurt door de isotopencurve van de ijskernen lineair uit te rekken zodanig dat de punten waar de scherpe temperatuurstijgingen voorkomen overeenstemmen. Dit onderzoek is een bewijs dat de D/O cycli terug te vinden zijn in zeesedimenten van de Noord-Atlantische oceaan en dat, althans voor de laatste 80000 jaar, de atmosfeer en de oceaanoppervlakte een gekoppeld systeem zijn geweest in de Noord Atlantische regio.

Eén van de belangrijkste ontdekkingen in deze studie is de relatie tussen de ijskern temperatuur cycli en het voorkomen van de Heinrich events in de zeesedimenten van de Noord-Atlantische oceaan. Heinrich events doen zich blijkbaar voor op het moment van extreem koude stadialen gevolgd door een abrupte overgang naar een warmer klimaat.

\section{Zuidelijk Halfrond}

17 Abrupte klimaatswijzigingen komen niet enkel voor in de Atlantische regio. De meest overtuigende data zijn terug te vinden in de ijsarchieven. Chappellaz et al. (1993) stelden vast dat de hoeveelheid atmosferisch methaan $\left(\mathrm{CH}^{4}\right)$ belangrijke veranderingen onderging tijdens bijna alle D/O events van de laatste 45000 jaar. Dit is een direct bewijs van veranderingen in de hydrologische cyclus tijdens de $\mathrm{D} / \mathrm{O}$ events aangezien de bron van de veranderingen in atmosferisch methaan in de tropen en op lage breedten ligt.

Een veel gestelde vraag is of klimaatveranderingen in het noordelijk halfrond al of niet synchroon verlopen met die in het zuidelijk halfrond. In dit verband is de vergelijking tussen de ijskernen van Groenland en Antarctica een bruikbare strategie.

Temperatuursvariaties afgeleid van de $\delta^{18} \mathrm{O}$ curve in Groenland zijn gekarakteriseerd door een patroon van plotse snelle opwarming en geleidelijke langzame afkoeling. Antarctische temperatuursvariaties vertonen een verschillend patroon met minder, niet zo duidelijke en meer geleidelijke opwarmings- en afkoelingsevents. De grote uitdaging is dus om het mechanisme te vinden dat schuilt achter het verschillende gedrag van de hoge breedten van de noordelijke en zuidelijke hemisfeer.

Blunier et al. (1998) hebben aan de hand van variaties in $\mathrm{CH}_{4}$ in luchtbellen van twee Antarctische kernen (Byrd en Vostok) en de GRIP ijskern een synchronisatie opgesteld waarbij de relatieve fasering van het voorkomen van events in beide hemisferen kan worden vergeleken. De drie kernen worden gelinkt aan de GRIP tijdschaal (welke niet als absoluut kan worden beschouwd) over een periode van 50 kyr BP tot het begin van het Holoceen. Zij kwamen tot de conclusie dat tussen 47-23 kyr BP, antarctische klimaatveranderingen zich gemiddeld 1-2,5 kyr vroeger voordoen dan de Groenlandse. Antarctische opwarming is niet in fase met de corresponderende D/O events. Terwijl de Antarctische temperatuur reeds stijgt, blijft de temperatuur van Groenland dalen. De antarctische temperatuurstijging wordt onderbroken op het ogenblik dat de temperatuur boven Groenland naar een interstadiaal springt. Vanaf dan koelen beide hemisferen af tot glaciale situaties waarbij deze eerder bereikt worden in Antarctica. Het ziet er dus naar uit dat het zuiden het noorden "leidt". Later (Blunier en Brook, 2001) werd met dezelfde methode $\left(\mathrm{CH}_{4}\right)$ de antarctische Byrd kern gecorreleerd met de Groenlandse GISP2-kern waarbij eenzelfde patroon werd vastgesteld voor de laatste 90000 jaar.

21 Er is echter één belangrijke uitzondering, namelijk de Taylor Dome ijskern (oostantarctische kust, westelijke kant van de Ross Zee). Steig et al. (1998) kwamen bij vergelijking met de GISP2-kern tot de conclusie dat tijdens de laatste glaciaal- 
interglaciaal overgang de klimaatveranderingen synchroon of bijna synchroon verlopen in beide hemisferen.

\section{Welke mechanismen drijven de klimaatveranderingen en wat zijn de wisselwerkingen tussen atmosfeer, oceaan en continent?}

Zoals hiervoor reeds vermeld, zijn in Groenlandse ijskernen 24 milde periodes (D/O events) aangetroffen tijdens het laatste glaciaal. De temperatuur boven Groenland zou gecontroleerd worden door de warmte die vrijkomt aan de oppervlakte van de NoordAtlantische oceaan (Blunier et al., 1998; Bond et al., 1993). Dit warme zeewater wordt naar de Noord-Atlantisch oceaan getransporteerd door thermohaliene circulatie (THC) welke wordt geïnduceerd door de vorming van North Atlantic Deep Water of Noord Atlantisch Diep Water (NADW). Door de vorming van zeer koud en dus zwaarder water (NADW) dat naar de diepte zakt op de hogere breedten van de Atlantische oceaan, wordt een circulatie op gang gebracht (THC) waarbij warm oppervlaktewater van de lagere breedten naar het noorden stroomt. Veranderingen in de Atlantische THC worden verondersteld sterk gelinkt te zijn met ice-rafting of Heinrich events en geassocieerde smeltwatervorming; het vrijkomen van smeltwater zorgt ervoor dat de NADW vorming wordt verminderd met als gevolg een verkoeling in de Noord-Atlantische regio. De verkoeling op haar beurt vertraagt het smelten wat de vorming van NADW bevordert en voor plotse opwarming zorgt. Door de opwarming komt echter terug meer smeltwater in de oceaan wat dan zorgt voor een geleidelijke stopzetting van de NADW-vorming (Blunier et al., 1998). De vraag is nu wat de oorzaak is van de ice-rafting events en de gekoppelde smeltwatervorming. Blunier et al. (1998) zien een Antarctische opwarming als mogelijke oorzaak van een ice rafting event (mogelijk door een stijging van de zeespiegel). D/O events en corresponderende ice-rafting events komen echter meer voor dan Antarctische opwarmingen dus ice rafting events kunnen slechts gedeeltelijk worden geïnduceerd door Antarctische opwarming. Voor de D/O events die niet gekoppeld zijn aan een opwarming in Antarctica, weerhouden Blunier et al. (1998) interne processen binnen de ijskappen, die resulteren in het afbreken van ijsbergen in de Noord-Atlantische oceaan, als een mogelijk mechanisme voor de aanzet van ice-rafting events.

Het mechanisme van NADW beïnvloedt de diep-water-circulatie op wereldschaal waardoor kan worden gesteld dat klimaatverandering gekoppeld aan de NoordAtlantische THC gevolgen moet hebben op wereldvlak. Oceaanmodellen suggereren dat een sterkere NA-THC tot afkoeling leidt van minstens bepaalde delen van de zuidelijke hemisfeer en tot opwarming leidt van de hogere breedten van de noordelijke hemisfeer. Omgekeerd zal een stopzetten van de THC, wat een snelle afkoeling in de noordelijke hemisfeer tot gevolg heeft, een opwarming in de zuidelijke hemisfeer veroorzaken omdat warmte niet langer noordwaarts wordt getransporteerd. Dit fenomeen wordt de bipolar seesaw genoemd (Blunier and Brook, 2001).

De vergelijking tussen de antarctische Byrd en Vostok kernen en de Groenlandse GRIP kern brengen een asynchroon patroon naar voor tussen beide hemisferen waarbij de veranderingen zich vroeger voordoen in het hoge zuiden dan in het hoge noorden. Echter, bij een vergelijking tussen de antarctische ijskern Taylor Dome (oost-antarctische kustsite, westelijke kant van de Ross Zee) en de Groenlandse GISP2 kern (Steig et al., 1998) kwam men tot de conclusie dat gedurende de laatste glaciale/interglaciale overgang, de klimaatveranderingen synchroon of bijna synchroon verlopen in beide hemisferen. De 
verschillen in de isotopen-temperatuurgeschiedenis van Taylor Dome en de andere antarctische kernen zijn te groot om toegeschreven te worden aan dateringsfouten (Steig et al., 1998). De resultaten wijzen er eerder op dat de gevolgen van de veranderingen in NADW op het circum-polaire klimaat van Antarctica, niet overal gelijk zijn.

Of meer: misschien zijn de veranderingen in de THC niet de directe en enige oorzaak voor klimaatsconnectie tijdens de laatste deglaciatie. Bard et al. (1997) kwamen tot deze conclusie aan de hand van de alkenone methode ${ }^{4}$ voor het bepalen van de SST op verscheidene zeekernen met hoge resolutie van de tropische Indische oceaan tussen $20^{\circ} \mathrm{N}$ en $20^{\circ} \mathrm{Z}$. Ze stelden vast dat de SST stijging ongeveer 15000 jaar geleden op $20^{\circ} \mathrm{Z}$ in fase is met de zee- en luchttemperatuursveranderingen in de noordelijke hemisfeer maar verscheidene millennia later begint dan de Antarctische opwarming. Aan de hand van deze vaststellingen kan men concluderen dat veranderingen in THC eventueel niet de enige oorzaak zijn geweest van "klimaatsteleconnectie" tussen beide hemisferen tijdens de laatste deglaciatie. Verwijzend naar Broecker (1996) sluiten Bard et al. niet uit dat THC een indirect effect heeft op de zuidelijke hemisfeer, door veranderingen in de dynamiek van de atmosfeer op lagere breedten te induceren. Volgens Broecker zou dit mechanisme kunnen verklaren waarom de grens van klimaatsasynchronie tussen beide hemisferen niet op de evenaar ligt maar op de Antarctische convergentie zone. Denton et al. (1999) komen tot een synchroon verloop van de laatste glaciale/ interglaciale overgang tussen beide hemisferen zowel voor het moment en de duur van de LGM (Last Glacial Maximum). Hun data zijn verkregen uit terrestrische bronnen (glaciale geologie en palynologie) uit de gemiddelde breedten van de zuidelijke hemisfeer (Andes, $40^{\circ} 35^{\prime}-42^{\circ} 25^{\prime} \mathrm{Z}$ ). Bovendien zoeken zij de klimaatslink tussen beide hemisferen eerder in de atmosfeer dan in de oceaan.

Hierbij kunnen we de volgende bedenking maken. Het lijkt erop dat de hoogste breedten en de lagere breedten van het zuidelijk halfrond anders reageren op de THC. Paleoklimatologisch onderzoek in de sub-Antarctische regio kan hier een uitkomst bieden; onderzoek van diepzeekernen of onderzoek op sub-Antarctische eilanden waarbij de vergelijking tussen eilanden welke een verschillende ligging (ten noorden of ten zuiden) ten opzichte van de huidige convergentiezone hebben - zou bijzonder interessant kunnen zijn.

\section{Klimaatswijzigingen in het Holoceen}

De aandacht van paleoklimatologen was de laatste decennia vooral gericht op de extreme wijzigingen die zich hebben voorgedaan tijdens het laatste glaciaal. In vergelijking daarmee lijkt het Holoceen ( \pm 11500 - 0 jaar geleden), dat door een relatief warm maar vooral stabiel klimaat wordt gekarakteriseerd, op basis van de isotopenstudie van de GRIP kern van Dansgaard et al. (1993), eerder een uitzondering te zijn, zelfs in vergelijking met het vorige interglaciaal, het Eemiaan ( $\pm 130000-116000$ jaar geleden (Kukla et al., 2002)). Over het al of niet stabiel zijn van het Eemiaan is men het echter nog niet eens. In verscheidene studies op basis van andere proxies (pollen, land/zee correlatie op basis van pollen, dinoflagellaten) komt men tot de conclusie dat het Eemiaan toch relatief stabiel zou zijn geweest (Cheddadi et al., 1998; Sánchez Goni et al., 2000) in tegenstelling tot de conclusies van Dansgaard et al. In een recente studie (NGRIP members, 2004) wordt gesteld dat het diepste deel van de bovengenoemde GRIP kern verstoord is door het plooien van ijs als gevolg van contact van het onderste gedeelte van de ijskap met het 
rotsgesteente. Bijgevolg zou de GRIP kern een vertekend beeld geven van het Eemiaan. Men is er tevens in geslaagd om een ongestoorde kern te nemen in noord Groenland die teruggaat tot 123000 jaar, dus tot in het Eemiaan. Hier komt men aan de hand van isotopen onderzoek op ijs tot de conclusie dat het Eem relatief stabiel en bovendien $5^{\circ} \mathrm{C}$ warmer zou zijn geweest dan het huidige interglaciaal.

De laatste jaren is er meer aandacht voor het Holoceen dat, hoewel de klimaatswijzigingen niet de amplitude hebben van die in het laatste glaciaal, toch meer variatie vertoont dan tot hiertoe algemeen werd aanvaard (Mayewski et al., 2004). Men kan dan ook dezelfde vragen stellen als deze van toepassing op het laatste glaciaal namelijk wat zijn de oorzaken van de klimaatswijzigingen; doen ze zich al of niet synchroon voor in de noordelijke en de zuidelijke hemisfeer en wat is het mechanisme van de koppeling tussen beide hemisferen?

Voor de discussie over het Holoceen gaan we uit van ons eigen regionaal paleoecologisch onderzoek op South Georgia, sub-Antarctica (Van der Putten et al., 2004). South Georgia is een langgerekt eiland (ca. $170 \mathrm{~km}$ lang en 2-34 km breed) gelegen in de zuid Atlantische oceaan $\left(54^{\circ} 30^{\prime}-55^{\circ} 00^{\prime} \mathrm{Z}, 35^{\circ} 30^{\prime}-38^{\circ} 30^{\prime} \mathrm{W}\right)$, ongeveer $1300 \mathrm{~km}$ ten oosten van de Falkland eilanden (fig. 1a). De Allardyce bergketen culmineert in Mount Paget met een hoogte van $2934 \mathrm{~m}$. Het huidige klimaat is koud-oceanisch met weinig seizoenale variatie. De gemiddelde jaartemperatuur bedraagt $+2.0^{\circ} \mathrm{C}$, augustus is de koudste maand met een gemiddelde temperatuur van $-1.2^{\circ} \mathrm{C}$ en februari is de warmste maand $\left(+5.6^{\circ} \mathrm{C}\right.$ gemiddeld). De noordelijke kust is gekenmerkt door diep ingesneden fjorden. Een permanente ijskap en gletsjers, die reiken tot op zeeniveau, bedekken $58 \%$ van de oppervlakte van het eiland. IJsvrije zones zijn bedekt met een toendra-achtige vegetatie. Door het sterk oceanisch klimaat is op de lagere gedeelten van het eiland een aanzienlijke veenbedekking ontwikkeld. 
Figuur 1. a. Lokalisatie van de sub-Antarctische eilanden; b. South Georgia met lokalisatie van het Tønsberg schiereiland (= Tønsberg Peninsula); c. Detailkaart van het Tønsberg schiereiland met lokalisatie van de site van de Tønsberg sequence.

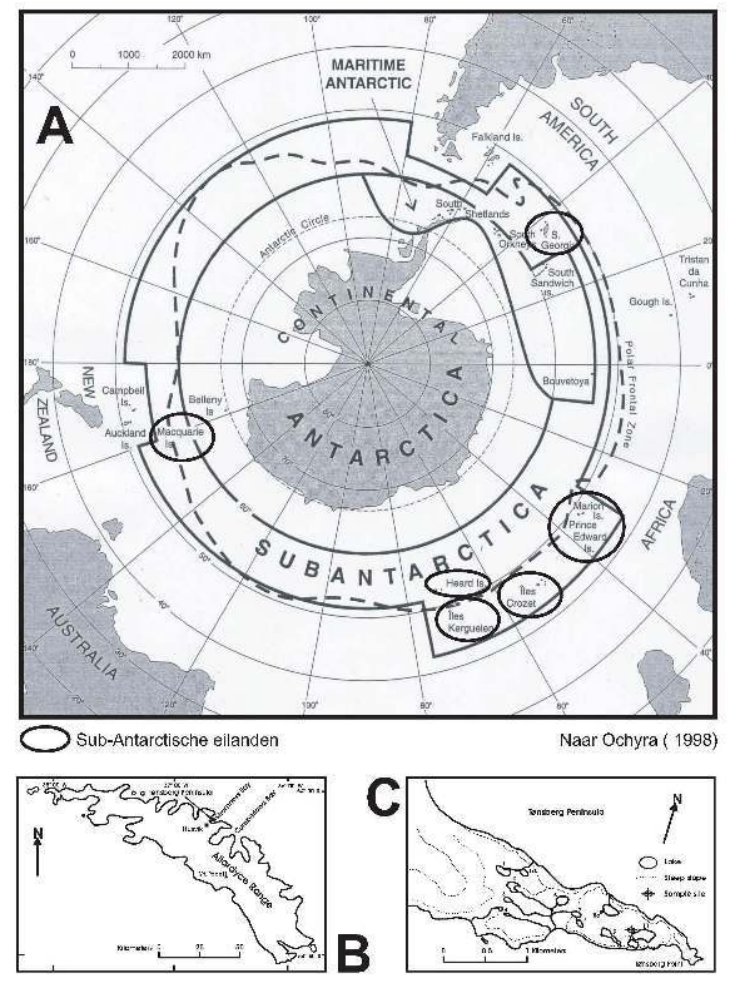

In 1992-93 hebben C. Verbruggen en L. Beyens (persoonlijke mededeling) een veldcampagne ondernomen in Husdal en op het Tønsberg schiereiland, in het zuidelijk deel van Stromness Bay (fig 1b). Tønsberg schiereiland, een uitloper van een transversale bergketen, splitst Stromness Bay in twee kleinere fjords. Glaciale erosie tijdens het laatste glaciaal vormde op het schiereiland meerdere depressies met een diameter van $10 \mathrm{~m}$ tot $200 \mathrm{~m}$, welke zijn opgevuld met water (fig. 1c). Op het uiteinde van het schiereiland ontdekte C. Verbruggen een kleine, relatief ondiepe depressie ( $40 \mathrm{~m}$ lang, $25 \mathrm{~m}$ breed en 3,20 m diep) opgevuld met veen. De depressie werd bemonsterd door het inslaan van een PVC-buis met een diameter van $11 \mathrm{~cm}$. Het is deze veensequentie die het onderwerp is geweest van een paleobotanische, -ecologische en -klimatologische studie.

De meest gebruikte techniek in paleo-ecologische onderzoek, namelijk palynologie (pollenanalyse), bleek echter beperkte resultaten op te leveren. Een palynologisch onderzoek door Van Parys (1995) van de Tønsberg sequentie bevestigde wat Barrow (1976, 1977, 1978, 1983) reeds had besloten. Verscheidene redenen kunnen worden gevonden voor deze palynologische deficiëntie. Slechts een twintigtal zaadplanten groeit op het boomloze eiland waarvan drie Juncaceae-species welke geen fossiel pollen opleveren. Vele species zijn reeds van in het begin van de registratie aanwezig en de pollencurves geven een vrij indifferent beeld. Macrorestenonderzoek leek een alternatief, zeker na de vaststelling dat in het venige sediment heel wat goed bewaarde mosresten aanwezig waren. De 3,20 m lange sequentie werd bemonsterd $\left(15-20 \mathrm{~cm}^{3}\right)$ om de $20 \mathrm{~cm}$ van de top tot een diepte van $180 \mathrm{~cm}$ en om de $10 \mathrm{~cm}$ beneden deze diepte. Deze stalen werden verwarmd in een $5 \% \mathrm{KOH}$ oplossing en daarna nat gezeefd op een zeef met maaswijdte van $250 \mu$. Onder een stereomicroscoop werden de mosresten en zaden per 
soort uitgepikt, gedetermineerd en gekwantificeerd waarna deze gegevens voorgesteld worden in een diagram. In de Tønsberg kern zijn 31 mostaxa gevonden waarvan de meeste konden worden gedetermineerd tot op soortniveau. Mossen vormen een belangrijke component van de hedendaagse vegetatie. Bovendien hebben heel wat soorten een beperkte ecologische niche en zijn ze gevoelig voor ecologische en klimatologische wijzigingen. Mossen zijn daarom geschikte indicatoren voor het registreren van wijzigingen in omgevingsfactoren (Jonsgard and Birks, 1995). Aan de hand van koolstofdateringen werd vastgesteld dat de depressie tenminste rond $11000 \mathrm{cal}$ BP ijsvrij was (Van der Putten en Verbruggen, 2005) en dat de kern ongeveer het volledige Holoceen weergeeft (11 500-0 cal yr BP).

Samenvattend kunnen we drie events in de Tønsberg kern onderscheiden, die klimaatsgebonden en dus onafhankelijk zijn van de lokale evolutie van het veen: de start van de sequentie na de deglaciatie (tenminste 11000 cal BP) onder warme klimatologische omstandigheden; een periode van non-depositie tussen 9000 en $8000 \mathrm{cal}$ BP met een plots vochtiger worden na 8000 BP; een duidelijk nattere periode na c. 2600 cal BP.

Voor South Georgia zijn de bestaande paleoklimatologische gegevens beperkt. Er bestaan enkele studies die ons in de mogelijkheid stellen onze resultaten te vergelijken. Rosqvist en Schuber (2003) komen aan de hand van Grey Scale Density ${ }^{5}$ en Loss on Ignition ${ }^{6}$ (LOI) analyse op meersedimenten (Block Lake), die de laatste 7000 jaar van het Holoceen beslaan, tot vier koelere periodes (7 200-7 000, 5 200-4 400, 2 400-1 600, na 1000 cal BP) (fig. 2). De overgang naar een nattere periode rond $2600 \mathrm{cal}$ BP vastgesteld in de Tønsberg kern wordt eveneens teruggevonden in de Block Lake sequentie hoewel de lage LOIwaarden geïnterpreteerd worden als een verkoeling van het klimaat. Clapperton et al (1989) stellen vast dat de grootste Holocene gletsjeruitbreiding op South Georgia culmineert rond c. $2200{ }^{14} \mathrm{C}$ BP (c. $2200 \mathrm{cal} \mathrm{BP}$ ). Deze $2600 \mathrm{BP}$ event lijkt een mondiaal karakter te hebben. Van Geel et al. $(1996,2000)$ geven een overzicht van de registratie van deze event (koud en/of nat) over de wereld verspreid. Heusser (1995), koppelt een toename van de plant Astelia pumila rond $2630 \pm 90$ BP in een veenafzetting in subAntarctisch Argentinië $\left(54^{\circ} 58^{\prime} \mathrm{Z}, 66^{\circ} 44^{\prime} \mathrm{W}\right)$ aan een plotse daling in temperatuur en een natter en stormachtiger klimaat. 
Figuur 2. Schematische voorstelling van de gepubliceerde paleoklimatologische data voor het eiland South Georgia.

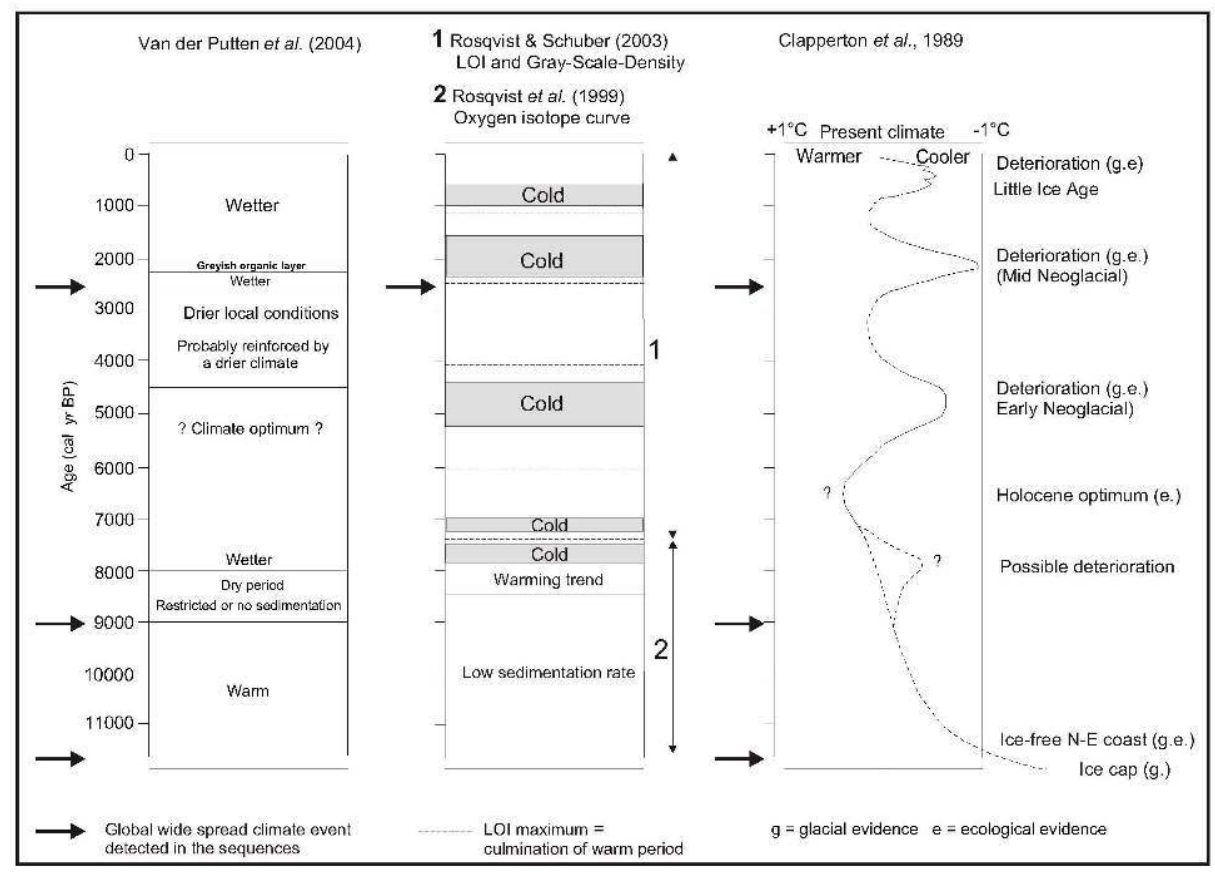

34 Voor de 9 000-8 000 cal BP event verwijzen we naar een tweede studie van Rosqvist et al. (1999) eveneens uitgevoerd op meersedimenten van South Georgia. Deze sequentie is genomen in een meer (Lake 1, fig.1c) op het Tønsberg schiereiland dat zich meer landinwaarts bevindt dan de Tønsberg kern. De kern beslaat een periode van c. 18500 tot $7000 \mathrm{cal}$ yr BP. Aan de hand van zuurstofisotopen onderzoek op biogene silica werd een temperatuurcurve opgesteld. Volgens deze resultaten blijft het relatief koud tot ongeveer $8400 \mathrm{cal}$ BP waarna een warme periode aanbreekt die kort wordt onderbroken door een koud event van 7800 tot 7400 cal BP.

Volgens de gegevens van de Tønsberg kern kan er echter geen twijfel bestaan over een duidelijke warme periode (begin van sedimentafzetting met aanwezigheid van heel wat plantensoorten) van bij het begin van het Holoceen. Deze warme periode wordt onderbroken door een hiaat rond 9000-8 $000 \mathrm{cal} \mathrm{BP}$. Dit is in overeenstemming met de conclusies uit een studie van holocene klimaatswijzigingen gebaseerd op isotopenonderzoek van 11 ijskernen van Antarctica (Masson et al., 2000). Het volledige Antarctische continent blijkt een warm optimum te vertonen tussen 11 500-9 $000 \mathrm{cal}$ BP gevolgd door een minimum rond $8000 \mathrm{cal}$ BP. Er is een opvallende temporele overeenkomst met de 8200 cal BP event aangetroffen in Groenlandse ijskernen (Alley et al ., 1997). Heiri et al. (2004) zijn aan de hand van chironomidenonderzoek ${ }^{7}$ in de Alpen tot de vaststelling gekomen dat er zich een sterke daling in zomertemperatuur voordoet in de periode van 8200 tot $7600 \mathrm{cal} \mathrm{BP}$.

Deze koude event blijkt dus eveneens een wereldwijd karakter te hebben (Stager and Mayewski, 1997) en is mogelijk geregistreerd in de Tønsberg kern onder de vorm van een hiaat eventueel als gevolg van drogere klimaatscondities aangezien het peil in de poel drastisch moet zijn verlaagd om de gelaagde sedimenten afgezet net voor het hiaat te verstoren (Van der Putten et al., 2004). De relatie tussen een algemeen aanvaarde koude 
event rond 8200 cal BP en "verdroging" in de Tønsberg site is niet direct evident. Er kan misschien een verband gevonden worden tussen non-depositie (hiaat) en een verkoeling, door de poel gedurende een langere periode te laten dichtvriezen. De koude periode in de kern van Rosqvist et al. (1999) start een duizendtal jaren later. In dit onderzoek is de event dus niet als dusdanig geregistreerd. In het kader van een overzichtsartikel in verband met wereldwijde Holocene klimaatswijzigingen (Mayewski et al., 2004) is, voor South Georgia, de studie van Rosqvist en Schuber (2003) opgenomen welke terug gaat tot 7000 cal BP en dus niet ver genoeg om de 8200 event te registreren. De Tønsberg kern registreert tussen 9000 en 8000 cal BP een wijziging in sedimentatie. Deze gebeurtenis kan echter op basis van de huidige gegevens niet met zekerheid gekoppeld worden met een kouder klimaat.

Een opmerking kan gemaakt worden bij de stelling van een warm optimum in het begin van het Holoceen resulterend uit onze paleobotanische gegevens en de link met de minimum ouderdom van deglaciatie van de lagergelegen delen van het eiland. Rosqvist $e t$ al. (1999) stellen namelijk dat het Tønsberg schiereiland en zelfs grotere laaggelegen delen van South Georgia al ijsvrij waren rond 18500 cal BP op basis van boven geciteerde meerkern. In Van der Putten en Verbruggen (2005) zijn data verzameld $\left({ }^{14} \mathrm{C}\right.$ dateringen van vroeg Holocene ouderdom van de basis van veenafzettingen en van een meerkern op het Tønsberg schiereiland) waaruit blijkt dat de site van Rosqvist et al. (1999) eerder een uitzondering is door haar atypische geomorfologische ligging. De ontdekking van een ijsvrije lokatie tijdens de Last Glacial Maximum wijst echter op de mogelijkheid van het bestaan van refugia waar planten het laatste glaciaal mogelijk hebben "overwinterd". Het feit dat in de Tønsberg kern heel wat plantensoorten (zowel hogere planten als mossen) aanwezig zijn van in het begin van de registratie wijst in dezelfde richting.

\section{Mogelijke oorzaken van de holocene klimaatswijzigingen}

Enkel de hoger besproken events namelijk de "8 200 koude event" en de "2 600 koude/ natte event" worden hier behandeld.

Voor de events die zich tijdens het glaciaal en tijdens de deglaciatie voordeden worden, als mechanisme, verstoringen in de thermohaliene circulatie (THC) naar voor geschoven. De vraag is nu of er voor de events in het Holoceen, die kleiner zijn in amplitude, eveneens een link bestaat tussen wijzigingen in temperatuur (en vochtigheid) en wijzigingen in oceaancirculatie.

Wijzigingen in THC blijken zeker voor de 8200 event een belangrijke rol te spelen. Deze event is uniek voor het Holoceen in die zin dat de event zich voordoet op een moment dat er nog aanzienlijke ijskappen voorkomen in het noordelijk halfrond. Barber et al. (1999) geven, als oorzaak van de verminderde THC, een plotse drainage (c. $8450 \mathrm{yr}$ BP) van de toenmalige proglaciale meren Agassiz en Ojibay (aanvankelijk afgedamd door een restant van de Laurentische ijskap) in de Labrador Zee via Hudson Bay en Hudson Strait. Een dergelijke plotse zoetwatertoevoer vermindert de saliniteit van de oceaanoppervlakte en bijgevolg de THC met de meest abrupte en wijd verspreide koude event tijdens het Holoceen tot gevolg.

41 Een andere mogelijke oorzaak van gewijzigde THC zijn latitudinale verschuivingen in de grootste drift-ijs uitreidingen in de Noord Atlantische oceaan als gevolg van wijzigingen in energie afkomstig van de zon (Bond et al. 2001, Heiri et al., 2004). Veranderingen in 
drift-ijs uitbreiding kunnen de saliniteit van het Noord-Atlantische oppervlaktewater beïnvloeden en bijgevolg de THC.

Heiri et al. (2004) besluiten uit hun chironomidenonderzoek in de Alpen dat de door smeltwater veroorzaakte wijzigingen in de THC de meest dominante faktor is voor de holocene zomertemperatuurwijzigingen in centraal Europa. Magny (2004) komt echter door onderzoek naar veranderingen in meerniveau's in centraal Europa gedurende het Holoceen (hogere meerniveau's wijzen op een koeler en natter klimaat) en vergelijking van deze data met Noord Atlantische IRD (Ice Rafted Debris) data, de GISP2 ijskern en ${ }^{14} \mathrm{C}$ gegevens, tot de conclusie dat veranderingen in zonneactiviteit een belangrijke rol speelden in de holocene klimaatswijzigingen. De oceaan zou mogelijk de gevolgen van een relatief kleine wijziging in zonneradiatie hebben versterkt.

Voor de 2600 BP event verwijzen we naar van Geel et al (1996) die, gelijktijdig met de klimaatswijziging, een plotse toename van ${ }^{14} \mathrm{C}$ in de atmosfeer vaststelden. Later (van Geel et al., 2000) werd de toename in ${ }^{14} \mathrm{C}$ gekoppeld aan een abrupte daling van zonneactiviteit met een klimaatverandering als gevolg. Wijzigingen in zonneactiviteit hebben een globaal karakter wat wereldwijde registratie van de 2600 BP event zou kunnen verklaren. De 8200 event blijkt eveneens een wereldwijde verspreiding te hebben. Indien echter de zoetwaterinflux in de Noord Atlantische oceaan van beide proglaciale meren verantwoordelijk is voor de event met een verminderde THC als gevolg, dan kunnen we ons de vraag stellen waarom geen asynchronie voorkomt tussen beide hemisferen zoals vastgesteld in het glaciaal aan de hand van vergelijking tussen bepaalde Antarctische en de Groenlandse ijskernen. Dit zou kunnen pleiten voor de verklaring van verscheidene auteurs (Bond et al., 2001; van Geel et al., 1999; Magny, 2004), die een veranderende zonneactiviteit vooropstellen als oorzaak van de holocene klimaatsinstabiliteit.

In een overzichtsartikel (Rohling E.J. \& Pälike H., 2005) "ontkoppelen" de auteurs het 8200 yr BP koude event vastgesteld in de Noord Atlantische regio, gerelateerd aan een vermindering in THC als gevolg van een smeltwater toevoer in de Noord Atlantische oceaan, van een verscheidene eeuwen durende (c. 8600-8000 cal yr BP) klimaatsverkoeling welke ongeveer wereldwijd wordt gedetecteerd aan de hand van goed gedateerde klimaatsgegevens. Bovendien wordt verandering in zonneactiviteit als mogelijke oorzaak voor de aanzet van deze koelere periode naar voor geschoven (welke dus duidelijk vroeger begint dan het moment van toevoer van zoetwater in de Noord Atlantische oceaan met de 8200 BP koude event als gevolg). De Noord Atlantische 8200 koude event (c. 100 jaar durend) kan dus een relatief lokale klimaatsdeterioratie zijn "geprojecteerd" op een patroon van langer durende klimaatswijzigingen gedurende het Holoceen waarvan de laatste de Kleine IJstijd (1450-1850 n.C) is. Dit patroon vertoont bovendien een zeer goede correlatie met de fluctuaties in zonneactiviteit vastgesteld in het Holoceen.

\section{Conclusie}

Uit bovenstaand onderzoek mag blijken dat onderzoek op sub-Antarctische eilanden een belangrijke bijdrage kan leveren in het paleoklimatologisch onderzoek op wereldvlak. Deze eilanden zijn de enige landmassa's aanwezig in de circum-Antarctische oceaan en vertegenwoordigen dus belangrijke terrestrische archieven naast de mariene sedimenten en de ijskernen. Bovendien hebben ze een verschillende ligging ten aanzien van het 
actuele Polair Front (voorheen Antarctische Convergentie) (fig. 1): Crozet, Macquarie, Marion en Prince Edward liggen ten noorden van deze grens tussen gematigd en koud zeewater. South Georgia en Heard liggen ten zuiden ervan en Kerguelen ligt ongeveer ter hoogte van het Polair Front. Vergelijkend paleoklimatologisch onderzoek op deze eilanden en confrontatie van deze resultaten met bestaande gegevens van terrestrisch onderzoek op het Antarctisch continent, ijskernen en mariene kernen zal ongetwijfeld bijdragen tot het verder uitrafelen van de grote klimatologische vraagstukken van onze aarde.

Het Laboratorium voor Paleo-ecologie en Landschapsgenese van de Vakgroep Geografie, Universiteit Gent, onder leiding van C. Verbruggen, heeft tot op heden vier veldcampagnes op twee verschillende eilanden uitgevoerd: 1992-93 (Verbruggen en Beyens) en 1995-96 (Verbruggen en Van der Putten) op South Georgia; 1998-99 en 2001 (Verbruggen en Van der Putten) op de Crozet-Archipel.

\section{BIBLIOGRAPHIE}

ALLEY R.B., MAYEWSKI P.A., SOWERS T., STUIVER M., TAYLOR K.C. \& CLARK P.U., (1997), "Holocene climatic instability: a prominent, widespread event 8200 yr ago", Geology 25, pp. 483-486.

BARBER, D. C., DYKE, A., HILLAIRE-MARCEL, C., JENNINGS, A. E., ANDREWS, J. T., KERWIN, M. W., BILODEAU, G., MCNEELY, R., SOUTHON, J., MOREHEAD, M. D. \& GAGNON, J.-M. (1999), "Forcing of the cold event of 8,200 years ago by catastrophic drainage of Laurentide lakes", Nature 400, pp. 344-348.

BARD, E., ROSTEK, F. \& SONZOGNI, C. (1997), "Interhemipheric synchrony of the last deglaciation inferred from alkenone palaeothermometry”, Nature 385, pp. 707-710.

BARROW, C. J. (1976), "Palynological studies in South Georgia: I. Pollen and spore morphology of the native vascular species", British Antarctic Survey Bulletin 43, pp. 63-75.

BARROW, C. J. (1977), Palynological studies in South Georgia, Ph-D thesis, University of Birmingham.

BARROW, C. J. (1978), "Postglacial pollen diagrams from South Georgia (sub-Antarctic) and West Falkland Island (South Atlantic)”, Journal of Biogeography 5, pp. 251-274.

BARROW, C. J. (1983), "Palynological studies in South Georgia: III. Three profiles from near King Edward Cove, Cumberland East Bay”, British Antarctic Survey Bulletin 58, pp. 43-60.

BLUNIER T. \& BROOK E.J. (2001), “Timing of millennial-scale climate change in Antarctica and Greenland during the Last Glacial Period”, Science 291, pp. 109-112.

BLUNIER T., CHAPPELLAZ J., SCHWANDER J., DÄLLENBACH A., STAUFFER B., STOCKER T.F., RAYNAUD D., JOUZEL J., CLAUSEN H.B., HAMMERS C.U. \& JOHNSEN S.J. (1998), “Asynchrony of Antarctic and Greenland climate change during the last glacial period", Nature 394, pp. 739-743.

BOND G., BROECKER W., JOHNSEN S., MCMANUS J., LABEYRIE L., JOUZEL J. \& BONANI G. (1993), "Correlations between climate records from North Atlantic sediments and Greenland ice", Nature 365, pp. 143-147. 
BOND G., KROMER B., BEER J., MUSCHELER R., EVANS M.N., SHOWERS W. HOFFMANN S., LOTTIBOND R., HAJDAS I. \& BONANI G. (2001), "Persistent solar influence on North Atlantic Climate during the Holocene", Science 294, pp. 2130-2136.

BROECKER W.S., BOND G., KLAS M., CLARK E. \& MCMANUS J. (1992), “Origin of the northern Atlantic's Heinrich events", Climate Dynamics 6, pp. 265-273.

BROECKER W.S. (1996), "Paleoclimatology” Geotimes 41, pp. 40-41.

CHAPPELLAZ, J., BLUNIER, T., RAYNAUD, D., BARNOLA, J.-M., SCHWANDER, J. \& STAUFFER, B. (1993), "Synchronous changes in atmospheric $\mathrm{CH} 4$ and Greenland climate between 40 and $8 \mathrm{kyr}$ BP”, Nature 366, pp. 443-445.

CHEDDADI R., MAMAKOVA K., GUIOT J., DE BEAULIEU J.-L., REILLE M., ANDRIEU V., GRANOSZEWSKI W., \& PEYRON O. (1998), "Was the climate of the Eemian stable? A quantitative climate reconstruction from seven European pollen records", Palaeogeography, Palaeo climatology, Palaeoecology 143, pp. 73-85.

CLAPPERTON, C. M., SUGDEN D. E., BIRNIE J. \& WILSON M. J. (1989), "Late-Glacial and Holocene Glacier fluctuations and Environmental Change on South Georgia, Southern Ocean", Quaternary Research 31, pp. 210-228.

DANSGAARD W., JOHNSEN S.J., CLAUSEN H.B., DAHL-JENSEN D., GUNDESTRUP N.S., HAMMER C.U., HVIDBERG C.S., STEFFENSEN J.P., SVEINBJÖRNSDOTTIR A.E., JOUZEL J. \& BOND G. (1993), "Evidence for general instability of past climate from a 250-kyr ice-core record", Nature 364, pp. 218-220.

DENTON G.H., HEUSSER C.J., LOWEL T.VG., MORENO P.I., ANDERSEN B.G., HEUSSER L.E., SCHLÜHTER C. \& MARCHANT D.R. (1999), "Interhemispheric linkage of paleoclimate during the last glaciation”, Geografiska Annaler 81, pp. 107-153.

HEINRICH H. (1988), “Origin and consequences of Cyclic Ice Rafting in the Northeast Atlantic Ocean during the past 130,000 years”, Quaternary Research 29, pp. 142-152.

HEIRI O, TINNER W. \& LOTTER A.F. (2004), "Evidence for cooler European summers during periods of changing meltwater flux to the North Atlantic", PNAS 101, pp. 15285-15288.

HEUSSER C.J. (1995), “Palaeoecology of a Donatia-Astelia cushion bog, Magellanic-MoorlandSubantarctic Evergreen Forest transition, Southern Tierra del Fuego, Argentina”, Review of Palaeo botany and Palynology 89, pp. 429-440.

JONSGARD B. \& BIRKS H. H. (1995), “Late-glacial mosses and environmental reconstructions at Kråkenes, western Norway”, Lindbergia 20, pp. 64-82.

KUKLA, G. J., BENDER, M. L., DE BEAULIEU, J.-L., BOND, G., BROECKER, W. S., CLEVERINGA, P., GAVIN, J. E., HERBERT, T. D., IMBRIE, J. \& JOUZEL, J. (2002), “Last Interglacial Climates", Quaternary Research 58, pp. 2-13.

MAGNY M. (1995), Une histoire du climat, des derniers mammouths au siècle de l'automobile, Editions Errance, Paris.

MAGNY M. (2004), "Holocene climate variability as reflected by mid-European lake-level fluctuations and its probable impact on prehistoric human settlements", Quaternary International 113 , pp. 65-79.

MARTINSON D.G., PISIAS N.G., HAYS J.D., IMBRIE J., MOORE T.C.JR. \& SHACKLETON N.J. (1987), "Age dating and the Orbital Theory of the Ice Ages: Development of a high-resolution 0 to 300,000-year chronostratigraphy", Quaternary Research 27, pp. 1-29. 
MASSON, V., VIMEUX, F., JOUZEL, J., MORGAN, V., DELMOTTE, M., CIAIS, P., HAMMER, C., JOHNSEN, S., LIPENKOV, V. Y. \& MOSLEY-THOMPSON, E. (2000), "Holocene Climate Variability in Antarctica Based on 11 Ice-Core Isotopic Records", Quaternary Research 54, pp. 348-358.

MAYEWSKI P.A., ROHLING E.E, STAGER J.C., KARLÉN W., MAASCH K.A., MEEKER L.D., MEYERSON E.A., GASSE F., VAN KREVELD S., HOLMGREN K., LEE-THORP J., ROSQVIST G., RACK F., STAUBWASSER M., SCHNEIDER R.R. \& STEIG E.J. (2004), "Holocene climate variability", Quaternary Research 62, pp. 243-255.

NGRIP MEMBERS (2004), “High-resolution record of Northern Hemisphere climate extending into the last interglacial period”, Nature 431, pp. 147-151.

OCHYRA, R. (1998), The moss flora of King George Island, Antarctica, W. Szafer Institute of Botany, Polish Academy of Science, Cracow, Poland.

ROHLING E.J. \& PÄLIKE H. (2005), “Centennial-scale climate cooling with a sudden cold event around 8,200 years ago", Nature 434, pp. 975-978.

ROSQVIST, G.C., RIETTI-SHATI, M. \& SHEMESH, A. (1999), "Late glacial to middle Holocene climatic record of lacustrine biogenic silica oxygen isotopes from a Southern Ocean island", Geology 27, pp. 967-970.

ROSQVIST G.C. \& SCHUBER P. (2003), "Millennial-scale climate changes on South Georgia, Southern Ocean”, Quaternary Research 59, pp. 470-475.

SÁNCHEZ GONI M.F., TURON J.-L., EYNAUD F. SHACKLETON N.J. \& CAYRE O. (2000), “Direct land/ sea correlation of the Eemian, and its comparison with the Holocene: a high-resolution palynological record off the Iberian Margin", Geologie en Mijnbouw/ Netherlands Journal of Geosciences 79,pp. 345-354.

STAGER J.C. \& MAYEWSKI P.A. (1997), “Abrupt Early to Mid-Holocene Climatic transition registered at the Equator and the poles”, Science 276, pp. 1834-1836.

STEIG E.J., BROOK E.J., WHITE J.W.C., SUCHER C.M., BENDER M.L., LEHMAN S.J., MORSE D.L., WADDINGTON E.D. \& CLOW G.D. (1998), "Synchronous climate changes in Antarctica and the North Atlantic", Science 282, pp. 92-95.

STOCKER, T. F. (2000), "Past and Future reorganisations in the Climate system", Quaternary Science Reviews 19, pp. 301-319.

VAN DER PUTTEN N., STIEPERAERE H., VERBRUGGEN C. \& OCHYRA R. (2004), “Holocene palaeoecology and climate history of South Georgia (sub-Antarctica) based on a macrofossil record of bryophytes and seeds", The Holocene 14, pp. 382-392.

VAN DER PUTTEN N. \& VERBRUGGEN C. (2005), "The onset of deglaciation of Cumberland Bay and Stromness Bay, South Georgia", Antarctic Science 17, pp. 29-32.

VAN GEEL B., BUURMAN J., WATERBOLK H.T. (1996), “Archaeological and palaeoecological indications of an abrupt climate change in The Netherlands, and evidence for climatological teleconnections around 2650 BP", Journal of Quaternary Science 11, pp. 451-460.

VAN GEEL B., RASPOPOV O.M., RENSSEN H., VAN DER PLICHT J., DERGACHEV V.A., MEIJER H.A.J. (1999), “The role of solar forcing upon climate change", Quaternary Science Reviews 18, pp. 331-338.

VAN GEEL B., HEUSSER C.J., RENSSEN H. \& SCHUURMANS C.J.E. (2000), “Climatic change in Chile at around 2700BP and global evidence for solar forcing: a hypothesis", The Holocene 10, pp. 659-664. 
VAN PARYS V. (1995), Paleoecologisch onderzoek op South Georgia (peri-Antarctica),

Licentiaatsscriptie, Universiteit Gent.

WESTERHOFF W.E., DE MULDER F.J., GELUK M.C., RITSEMA I., \& WONG Th. E. (eds.) (2003), De

ondergrond van Nederland, Nederlands Instituut voor Toegepaste Wetenschappen, TNO, 380 p.

\section{NOTES}

1. Zuurstof aanwezig in water bevat de stabiele isotopen ${ }^{18} \mathrm{O}$ en ${ }^{16} \mathrm{O}$.

Het gebruik van de ${ }^{18} \mathrm{O} /{ }^{16} \mathrm{O}$-verhouding is gebaseerd op twee vaststellingen:

Bij verdamping van oceaanwater bevat de waterdamp een lagere hoeveelheid aan ${ }^{18} \mathrm{O}$ en bij condensatie zal de hoeveelheid ${ }^{18} \mathrm{O}$ groter zijn in het water dan in de waterdamp.

De verhouding ${ }^{18} \mathrm{O} /{ }^{16} \mathrm{O}$ is afhankelijk van de temperatuur; de hoeveelheid ${ }^{18} \mathrm{O}$ in neerslag vermindert wanneer de temperatuur daalt (Magny, 1995).

2. Dansgaard/Oeschger events hebben een opvallende temporele evolutie: het klimaat koelt af gedurende verscheidene eeuwen tot $3 \mathrm{kyr}$, terwijl opwarming plots gebeurt en over een zeer korte periode (jaren tot enkele decennia) (Stocker, 2000).

3. In 1988 publiceerde Heinrich een studie waarin hij bijzondere sedimentlagen in sequenties van het laatste glaciaal (Weichsel) van de oostelijke Noord-Atlantische oceaan beschrijft en verklaart. De lagen zijn te onderscheiden van de normale glaciale diepzeesedimenten door een verschillende sedimentsamenstelling (rijk aan ice-rafted debris) en een lage concentratie aan foraminiferen. Ze zijn ontstaan door het afsmelten van landsediment-dragende-ijsbergen afkomstig van de grote noordelijke ijskappen tijdens periodes waarbij ijsbergen zich ver in de Noord-Atlantisch oceaan hebben verspreid. Deze lagen van grove lithische sedimenten gevonden in marine sedimenten werden later Heinrich Events genoemd (Broecker et al. 1992).

4. Geochemische methode waarbij chemische eigenschappen van alkenonen worden gemeten in specifieke soorten algen bewaard in diepzeesedimenten (Coccolieten). Er bestaat een verband tussen de chemische eigenschappen van alkenonen en de groeitemperatuur van de algen.

5. X-stralen onderzoek van sedimenten met bijhorende beeldverwerking.

6. Het bepalen van de hoeveelheid van organische stof in het sediment door verbranding van het monster bij een bepaalde temperatuur.

7. Paleoklimatologische proxie waarbij de resten van larven van chironomiden (dans- of vedermuggen), bewaard in meersedimenten, worden onderzocht. De larven van chironomiden leven in water (meren, rivieren) en zijn voor hun ontwikkeling sterk gekoppeld aan de heersende zomertemperatuur. Aan de hand van chironomidenonderzoek kan men dus de zomertemperatuur in het verleden reconstrueren.

\section{RÉSUMÉS}

Klimaatswijzigingen in het verleden zijn geregistreerd in zowel terrestrische, ijs- als diepzeekernen. De laatste 10 jaar is paleoklimatologisch onderzoek vooral toegespitst op het temporeel correleren van deze verschillende data en het zoeken naar een mechanisme (oorzaken en gevolgen) dat achter de klimatologische wijzigingen, die wereldwijd zijn geregistreerd, schuilt. De Noord-Atlantische regio is de best gekende regio enkel en alleen door de 
aanwezigheid van een groot aantal data in de drie domeinen. De klimaatscurves van het zuidelijk halfrond zijn vooral afkomstig van de Antarctische ijskap. Diepzee en terrestrisch paleoklimatologisch onderzoek is hier "ondervertegenwoordigd" en het belang in de paleoklimaatsdiscussie van sub-Antarctische eilanden werd in het verleden eerder "verwaarloosd". Echter, het beperkte aantal gepubliceerde studies en onze eigen gegevens geven aan dat op deze eilanden een groot potentieel aan bruikbare terrestrische archieven aanwezig is, bovendien de enige terrestrische archieven in de circum-Antarctische oceaan.

Past climate change is studied in terrestrial, deep ocean and ice cores. For the last ten years, climatological research has been focused on climatic connections between data from different sources and environments on earth and on the driving mechanism behind these climatic connections. The North Atlantic region is the best known region only because of the many palaeoclimatological data present in this area. Past climate change in the Southern Hemisphere has been attained especially by research of Antarctic ice cores. The number of studies of terrestrial and oceanic cores in the Southern Hemisphere is lower than in the north. The significance of the sub-Antarctic region for the palaeoclimatological discussion has been rather 'neglected' in the past. However, the restricted published data and our own research show that sub-Antarctic islands have a great potential for high resolution terrestrial palaeoclimatological research. Moreover, these islands represent the only terrestrial archives in the circum-Antarctic ocean.

\section{INDEX}

Keywords : palaeoclimatology, North-Atlantic region, Southern hemisphere, sub-Antarctic, South Georgia, Holocene

motsclesnl paleoklimatologie, Noord-Atlantische regio, zuidelijk halfrond, sub-Antarctica, Holoceen

\section{AUTEUR}

\section{NATHALIE VAN DER PUTTEN}

Universiteit Gent, nathalie.vanderputten@ugent.be 